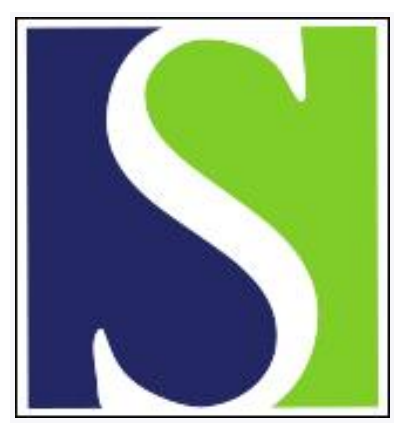

Scand J Work Environ Health 2002;28(5):328-332

https://doi.org/10.5271/sjweh.682

Issue date: Oct 2002

Healthy worker effect in cohort studies on chronic bronchitis

by Radon K, Goldberg M, Becklake M

Affiliation: Institute of Occupational and Environmental Medicine, Ziemssenstrasse 1, DE-80336 Munich, Germany. Katja.Radon@arbeits.med.uni-muenchen.de

The following articles refer to this text: 2006;32(2):132-138;

2008;34(3):224-229; 2012;38(1):70-77

Key terms: chronic bronchitis; cohort study; epidemiology; healthy worker effect; occupational medicine; selection bias

This article in PubMed: www.ncbi.nlm.nih.gov/pubmed/12432986

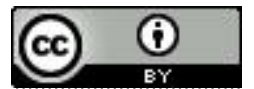




\title{
Healthy worker effect in cohort studies on chronic bronchitis
}

\author{
by Katja Radon, PhD, ${ }^{1}$ Mark Goldberg, PhD, ${ }^{1}$ Margaret Becklake, $M D^{1}$
}

\author{
Radon K, Goldberg M, Becklake M. Healthy worker effect in cohort studies on chronic bronchitis. Scand J Work \\ Environ Health 2002;28(5):328-332.
}

\begin{abstract}
Objectives Despite the recognition of selection biases arising from the healthy worker effect in occupational mortality studies, the possibility of similar effects in occupational cohort studies on respiratory symptoms is not well known. Two mechanisms are responsible for the healthy worker effect in respiratory cohort studies. One is health-based selection of workers into employment (healthy hire effect), and the other is health-based differential losses to follow-up (healthy worker survivor effect). The aim of the present paper was to estimate the magnitude of the healthy worker survivor effect in cohort studies of symptoms of chronic bronchitis.

Methods A meta-analysis of occupational cohort studies of symptoms of chronic bronchitis was performed that included published articles identified in searches of the Medline bibliographic databases between 1980 and March 2001 and the reference lists of the located articles.

Results Eight cohort studies were identified using an a priori selection criterion. The pooled odds ratio of the prevalence of chronic bronchitis for subjects leaving the cohorts was 1.23 when these subjects were compared with those who remained under study (95\% confidence interval 1.04-1.44).

Conclusions The prevalence of respiratory symptoms among exposed workers may be underestimated if the healthy worker survivor effect is not taken into account.
\end{abstract}

Key terms cohort studies, epidemiology, occupational medicine, selection bias.

The term "healthy worker effect" was first used to describe the lower-than-expected age-standardized mortality rate observed in many occupational studies (1). This phenomenon has been attributed to the use of an inappropriate reference group, namely, the general population (2-4). It has been suggested that membership in the workforce underlies three basic mechanisms (4-7): (i) primary selection at the time of hire ("healthy hire effect"), (ii) secondary selection during employment ("healthy worker survivor effect"), and (iii) changes in life in association with employment. As a result of these mechanisms, the workforce is, on the average, healthier than the general population.

In occupational cohort studies, subjects are selected into the cohort because of their employment in the fa- cility under consideration. This selection into the workforce might already be differential for those in the group exposed to a potential occupational hazard [eg, hemp workers (8)] as compared with the comparison group [eg, packers working in the same factory as the hemp workers but without exposure to noxious dusts or fumes (8)] because of a pre-employment medical examination and self-selection of the subject $(1,4,9)$.

Once employed, workers will eventually leave the workforce, and those who experience symptoms may leave earlier. Therefore, the duration of employment in the job may again differ for those potentially exposed and the comparison group. In addition, workers with symptoms are often transferred to jobs that do not entail the same types of exposures experienced in the

1 Department of Medicine, Joint Departments of Epidemiology and Biostatistics and Occupational Health, McGill University, 1020 Pine Avenue West, Montreal, Quebec, Canada.

Reprint requests to: Dr Katja Radon, Institute of Occupational and Environmental Medicine, Ziemssenstrasse 1, DE-80336 Munich, Germany. [E-mail: Katja.Radon@arbeits.med.uni-muenchen.de] 
workers' usual occupations. As a result, the distribution of employees among exposure categories is not random with respect to the outcome $(4-7,10)$.

While it is difficult to control for the healthy hire effect, one may be able to control appropriately for the healthy worker survivor effect by obtaining a complete follow-up of all the subjects until they leave the cohort or change workplaces when they experience symptoms. If it is not possible to trace subjects after they leave work, the magnitude of the healthy worker survivor effect can be estimated by comparing the prevalence of symptoms at the time of hire among those who left the cohort during the follow-up period to the prevalence of symptoms among those who remained at work.

Only one review of the healthy worker effect has been carried out in respiratory epidemiology (1), and the authors focused on cross-sectional surveys of measurements of lung function. It is of considerable interest to assess the healthy worker effect in occupational cohort studies of respiratory symptoms, and our paper presents an estimate of its magnitude in studies in which chronic bronchitis was assessed.

\section{Subjects and methods}

A Medline search was conducted using the key terms "occupational cohort" and "respiratory symptoms", and 163 papers were found. Additional articles were selected from the reference lists of the selected papers.

The following inclusion criteria were used: publication between January 1980 and March 2001 in English or German and report of a longitudinal, prospective occupational cohort study providing information on the baseline prevalence of respiratory symptoms for the exposed subjects who stayed in the cohort over the follow-up period and for those who were lost to followup.

For multiple publications of the same cohort, the most recent paper reporting the baseline data on symptoms was used. The meta-analysis was restricted to studies in which symptoms of chronic bronchitis were reported. For each study, the number of subjects who remained in the cohort, the number of subjects who were lost to follow-up over the study period, the industry under study, the duration of follow-up, the country of the survey, and descriptive data of the study population were abstracted from the papers. In addition, the number of workers who were symptomatic at the time of the baseline survey and remained in the cohort and the number of workers who were symptomatic at the time of the baseline survey and who were lost to follow-up were extracted. In order to estimate the health-based selection out of the workforce, we calculated the preva- lence of chronic bronchitis at the time of the baseline survey for those who stayed in the study population and those who were lost to follow-up. We computed odds ratios (OR) and $95 \%$ confidence intervals $(95 \% \mathrm{CI})$ for the prevalence of chronic bronchitis at the time of entry into the study by comparing the group of workers lost to follow-up with the group of workers who remained under study.

Using the inverse variance of each study as a weight (fixed-effects analysis), we calculated a pooled odds ratio as a weighted mean for the study results (11). In order to estimate the $95 \%$ confidence interval for the summary measure, the inverse of the square root of the sum of the weights was used as an estimate of the standard error. The chi-square test for the summary odds ratio was calculated as described by Rothman \& Greenland (11). Because of the small number of studies, random effects models could not be used.

\section{Results}

Overall, 233 papers were considered for the meta-analysis. (See the appendix; references are available from the authors by request.) The majority of the studies had to be excluded for reasons of design (6 review articles, 4 case reports, 62 cross-sectional studies, 7 case-referent studies, 13 retrospective cohort studies, 4 experimental studies, 4 mortality studies, and 16 population-based surveys). Moreover, 97 studies on respiratory symptoms did not focus on symptoms of chronic bronchitis. Four papers described additional observations on cohorts already included in the analysis. Eight occupational studies of chronic bronchitis did not provide separate baseline characteristics of the dropouts and subjects who were not lost to follow up. Among these latter studies, Westeel et al (12) reported a significantly higher proportion of chronic bronchitis for those excluded or lost to follow-up without giving exact prevalences. Chinn et al (13) found a significantly higher prevalence of chronic phlegm among the dropouts but did not report on chronic bronchitis among those who remained and those who left. Vestbo \& Rasmussen (14) found a higher proportion of chronic bronchitis for those who were lost to follow-up but did not report the prevalence of symptoms separately for the exposed subjects. The remaining surveys did not report on the baseline prevalence of symptoms for those who stayed in the cohort (15) or for those who were lost to follow-up (16-19).

Eight studies reporting the prevalence of chronic bronchitis at the beginning of the study were thus included in this analysis $(8,20-26)$. Two studies $(8,20)$ provided separate prevalences for the men and women in the cohort, one other study presented separate prevalences 
Table 1. Characteristics of the studies included in the meta-analysis. (ATS = questionnaire on respiratory symptoms published by the American Thoracic Society, BMRC = questionnaire published by the British Medical Research Council, CECA = questionnaire pour l'etude de la bronchite chronique et de l'emphyseme pulmonaire)

\begin{tabular}{|c|c|c|c|c|}
\hline Study & Occupation & Country & Questionnaire & $\begin{array}{l}\text { Duration of } \\
\text { follow-up (years) }\end{array}$ \\
\hline Zuskin et al, 1991 (20) a & Cotton textile workers & Croatia & BMRC & 10 \\
\hline Zuskin et al, 1991 (20) a & Cotton textile workers & Croatia & BMRC & 10 \\
\hline Christiani et al, 2001 (24) a & Cotton textile workers & China & ATS & 15 \\
\hline Zuskin et al, 1994 (8) a & Hemp workers & Croatia & BMRC & 3 \\
\hline Zuskin et al, 1994 (8) a & Hemp workers & Croatia & BMRC & 3 \\
\hline Zuskin et al, 1997 (21) a & Food processing & Croatia & BMRC & 2 \\
\hline Zuskin et al, 1997 (21) a & Food processing & Croatia & BMRC & 2 \\
\hline Zejda et al, 1992 (22) ${ }^{\mathrm{b}}$ & Grain workers & Canada & ATS & 4 \\
\hline Pham et al, $1986(25)^{b}$ & Iron miners & France & $\mathrm{BMRC}$ & 5 \\
\hline Musk et al, $1982(23)^{c}$ & Fre fighters & United States & No standard questions & 6 \\
\hline Mur et al, $1989(26)^{c}$ & Arc welders & France & CECA & 5 \\
\hline
\end{tabular}

a Definition of bronchitis: cough and phlegm for at least 3 months for at least 2 consecutive years.

b Definition of bronchitis: ATS criteria

c Definition of bronchitis: no details given.

Table 2. Characteristics of the subjects in the studies included in the meta-analysis. ( $M=$ male, $F=$ female)

\begin{tabular}{|c|c|c|c|c|c|c|c|c|c|}
\hline \multirow[t]{2}{*}{ Study } & \multirow{2}{*}{$\begin{array}{c}\text { Uncensored } \\
\qquad(\mathrm{N})\end{array}$} & \multirow{2}{*}{$\begin{array}{c}\text { Dropouts } \\
\text { (N) }\end{array}$} & \multirow{2}{*}{ s Gender } & \multicolumn{2}{|c|}{ Mean age (years) } & \multicolumn{2}{|c|}{ Mean duration of employment } & \multicolumn{2}{|c|}{ Smokers (\%) } \\
\hline & & & & Uncensored & Dropouts & Uncensored & Dropouts & Uncensored & Dropouts \\
\hline Zuskin et al, 1991 (20) & 31 & 13 & M &.. $\mathrm{a}$ &.. $\mathrm{a}$ & .. & .. &.. $\mathrm{a}$ &.. $\mathrm{a}$ \\
\hline Zuskin et al, 1991 (20) & 35 & 37 & $\mathrm{~F}$ & .. a & ... a &.. & .. & .. a & .. a \\
\hline Christiani et al, 2001 (24) & 346 & 101 & $\mathrm{M}: \mathrm{F}(1: 1.1)$ & 36.9 & 38.9 & 14.7 & 16.2 & 35.5 & 35.6 \\
\hline Zuskin et al, 1994 (8) & 28 & 1 & M & 43 &.. & 18 &.. & 93 &.. \\
\hline Zuskin et al, 1994 (8) & 38 & 10 & $\mathrm{~F}$ & 35 & .. & 12 & .. & 13 & .. \\
\hline Zuskin et al, 1997 (21) & 39 & 74 & $\mathrm{~F}$ & 31.8 & 35.3 & 13.7 & 13.7 & 0 & 0 \\
\hline Zuskin et al, 1997 (21) & 10 & 29 & $\mathrm{~F}$ & 25.7 & 23.6 & 5.8 & 3.3 & 100 & 100 \\
\hline Zejda et al, 1992 (22) & 51 & 113 & M & 20 & 20 & 0 & 0 & .. &.. \\
\hline Pham et al, 1986 (25) & 871 & 308 & M & 43.7 & 45 &.. &.. & 70.6 & 75.6 \\
\hline Musk et al, 1982 (23) & 951 & 821 & $M$ & 40.9 & 47.6 & 15.9 & 22.8 & 43.4 & 45.6 \\
\hline Mur et al, 1989 (26) & 300 & 79 & $M$ & 34.7 & 36.7 &.. &.. & $82^{b}$ & $78.5^{b}$ \\
\hline
\end{tabular}

${ }^{a}$ Mean age and prevalence of smoking not directly given, statement that variables did not differ between groups.

b Ourrent smokers and ex-smokers.

Table 3. Prevalence of chronic bronchitis at the time of entry into the studies included in the meta-analysis and the odds ratios (OR) with their $95 \%$ confidence intervals $(95 \% \mathrm{C})$ ).

\begin{tabular}{lrrrl}
\hline Study & $\begin{array}{l}\text { Prevalence of } \\
\text { chronic bronchitis a }{ }^{\text {(\%) }}\end{array}$ & OR & 95\% Cl \\
\cline { 2 - 3 } & Uncensored & Dropouts & & \\
\hline Zuskin et al, 1991 (20) & 19.4 & 30.8 & 1.85 & $0.42-8.11$ \\
Zuskin et al, 1991 (20) & 8.6 & 13.5 & 1.67 & $0.37-7.57$ \\
Christiani et al, 2001 (24) & 20.8 & 23.7 & 1.19 & $0.70-2.01$ \\
Zuskin et al, 1994 (8) & 39.3 & 100.0 & - &.. \\
Zuskin et al, 1994 (8) & 26.3 & 30.0 & 1.20 & $0.26-5.56$ \\
Zuskin et al, 1997 (21) & 10.3 & 9.5 & 0.91 & $0.25-3.34$ \\
Zuskin et al, 1997 (21) & 20.0 & 17.2 & 0.83 & $0.13-5.17$ \\
Zejda et al, 1992 (22) & 5.9 & 9.7 & 1.73 & $0.46-6.47$ \\
Pham et al, 1986 (25) & 23.9 & 32.5 & 1.53 & $1.15-2.04$ \\
Musk et al, 1982 (23) & 19.4 & 20.1 & 1.04 & $0.82-1.32$ \\
Mur et al, 1989 (26) & 3.3 & 5.0 & 1.55 & $0.47-5.07$ \\
\hline
\end{tabular}

for smokers and nonsmokers (21). These groups were considered independently of each other. Table 1 shows a description of the characteristics of these studies, while table 2 presents the characteristics of the subjects under study. The definitions of chronic bronchitis and the instruments used to measure the respiratory symptoms varied across these studies.

For each study, the prevalence of chronic bronchitis at the time of entry and the odds ratios for chronic bronchitis, comparing prevalences of the dropouts to those of the workers who stayed in the cohort, are given in table 3. Figure 1 shows the individual odds ratios for each study and the pooled odds ratio. There was no evidence of heterogeneity in the pooled estimate (chisquare test for homogeneity $=6.25,9$ degrees of freedom). A significantly elevated baseline prevalence of chronic bronchitis was found for the dropouts (pooled OR $1.23,95 \%$ CI 1.04-1.44). 


\section{Discussion}

The results of this meta-analysis indicate that a survival bias is likely to occur in occupational cohort studies on respiratory health if complete follow-up is not obtained for all workers. Our estimated pooled effect size may be an underestimation, as workers who were symptomfree at baseline may develop symptoms during the follow-up and subsequently quit their job (14). In addition, some persons may already have developed symptoms at an earlier point in time and therefore dropped out of the exposed population before the cohort study was initiated. There may also be a bias towards publishing positive results, although this possibility seems unlikely as the principal objectives of these studies was not related to making comparisons between subjects who left employment and those that did not. Studies with differential losses to follow-up may, however, be less likely to report these differences, especially in nonepidemiologic journals. In addition, these studies are less likely to be published. Therefore, publication bias may lead to an underestimation of the healthy worker survivor effect.

One limitation of our analysis is that we could not control for potential confounding factors such as age, duration of employment, gender, and smoking habits. At the begining of the studies those who left these cohorts were mostly comparable with respect to these factors with those who stayed (table 2); however, a moredetailed analysis could not be done. In addition, the precise definition of chronic bronchitis was not provided in all the studies, and the questions used to assess chronic bronchitis differed between the studies. Therefore, the assumption of homogeneity with respect to the outcome is not likely to be satisfied. However, as the estimate of relative risk was above unity in most of the studies involving different types of exposures, a wide range of follow-up periods and different age groups, this analysis indicates that the healthy worker survivor effect plays an important role in occupational cohort studies on respiratory health. Moreover, three of the eight studies that had to be excluded from our analyses also gave implications of a higher proportion of symptomatic subjects among those who dropped out of the cohort and thus supported our results $(12-14,27)$.

In all but two studies $(23,25)$, all the workers who did not participate in the follow-up survey had left the industry. Nevertheless, in the remaining studies, by Musk et al (23) and Pham et al (25), the dropouts were partly due to nonresponse. In the paper by Musk et al (23) the prevalence of respiratory symptoms was not given stratified for reason of dropout. In contrast, in the study of Pham et al (25), the observed health selection would have been even more pronounced if those who did not respond in the follow-up survey would have been excluded from the analysis.

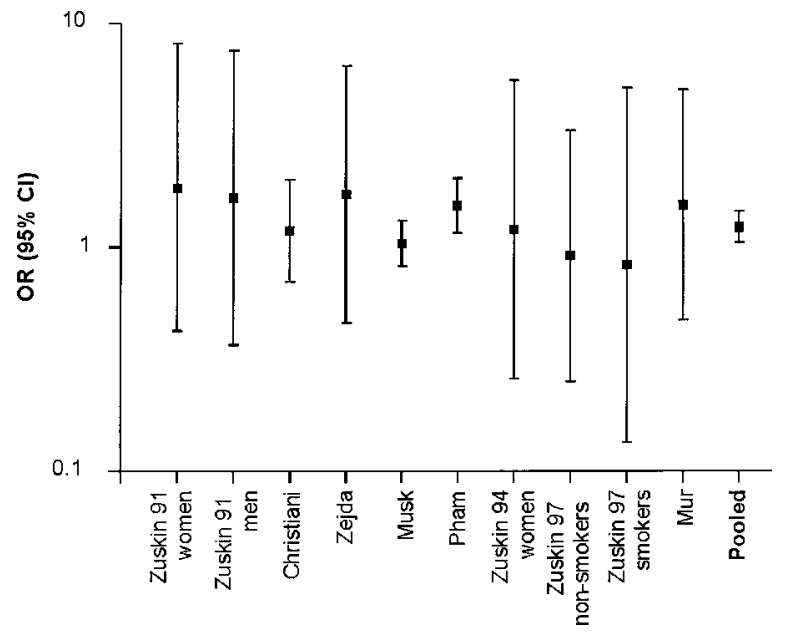

Figure 1. Odds ratio and $95 \%$ confidence intervals for symptoms of chronic bronchitis among workers who were lost to follow-up in comparison to those of workers who stayed in the cohort.

In summary, eight occupational cohort studies were identified that could be used to address the healthy worker survivor effect on chronic bronchitis. The results suggest that workers with symptoms of chronic bronchitis at the start of follow-up have a $23 \%$ higher risk of leaving the exposed cohort than persons without such symptoms. This finding, in turn, leads to an underestimation of the risk of disease for exposed workers if the healthy worker survivor effect is not taken into account.

\section{References}

1. Becklake MR, Lalloo U. The "healthy smoker": a phenomenon of health selection? Respiration 1990;57(3):137-44.

2. McMichael AJ. Standardized mortality ratios and the "healthy worker effect": scratching beneath the surface. J Occup Med 1976;18(3):165-8.

3. Wang J-D, Miettinen OS. Occupational mortality studies: principles of validity. Scand J Work Environ Health 1982; 8(3): 153-8.

4. Wen CP, Tsai SP. Anatomy of the health worker effect - a critique of summary statistics employed in occupational epidemiology. Scand J Work Environ Health 1982;8 suppl 1:4852.

5. Pearce N, Checkoway H, Shy C. Time-related factors as potential confounders and effect modifiers in studies based on an occupational cohort. Scand J Work Environ Health 1986;12(2):97-107.

6. Meijers JM, Swaen GM, Volovics A, Lucas LJ, van Vliet K. Occupational cohort studies: the influence of design characteristics on the healthy worker effect. Int J Epidemiol 1989; 18(4):970-5.

7. Arrighi HM, Hertz-Picciotto I. The evolving concept of the healthy worker survivor effect. Epidemiology 1994;5(2): 189-96.

8. Zuskin E, Mustajbegovic J, Schachter EN. Follow-up study 
of respiratory function in hemp workers. Am J Ind Med 1994;26(1):103-15.

9. Dosman JA, McDuffie HH, Pahwa P. Atopic status as a factor in job decision making in grain workers. J Occup Med 1991;33(9):1007-10.

10. Eisen EA. Healthy worker effect in morbidity studies. Med Lav 1995;86(2):125-138.

11. Rothman KJ, Greenland S. Modern epidemiology. 3rd ed. Philadelphia (PA): Lippincott Williams \& Wilkins, 1998.

12. Westeel V, Julien S, De Champs C, Polio JC, Mauny F, Gibey R, et al. Relationships of immunoglobulins E and G sensitization to respiratory function in dairy farmers. Eur Respir J 2000;16(5):886-92.

13. Chinn DJ, Cotes JE, el Gamal FM, Wollaston JF. Respiratory health of young shipyard welders and other tradesmen studied cross sectionally and longitudinally. Occup Environ Med 1995;52(1):33-42.

14. Vestbo J, Rasmussen FV. Baseline characteristics are not sufficient indicators of non-response bias follow up studies. J Epidemiol Community Health 1992;46(6):617-9.

15. Glindmeyer HW, Lefante JJ, Jones RN, Rando RJ, Weill H. Cotton dust and across-shift change in FEV1 as predictors of annual change in FEV1. Am J Respir Crit Care Med 1994; 149:584-90.

16. Mauny F, Polio JC, Monnet E, Pernet D, Laplante JJ, Depierre A, et al. Longitudinal study of respiratory health in dairy farmers: influence of artificial barn fodder drying. Eur Respir J 1997;10(11):2522-8.

17. Zuskin E, Mustajbegovic J, Schachter EN, Doko-Jelinic J, Budak A. Longitudinal study of respiratory findings in rubber workers. Am J Ind Med 1996;30:171-9.

18. Nielsen J, Bach E. Work-related eye symptoms and respiratory symptoms in female cleaners. Occup Med (Lond) 1999; 49(5):291-7.

19. Pham QT, Teculescu D, Meyer-Bisch C, Mur JM. Effects of chronic exposure to diisocyanates. Bull Eur Physiopathol Res 1987;23(6):561-4.

20. Zuskin E, Ivankovic D, Schachter EN, Witek TJ. A ten-year follow-up study of cotton textile workers. Am Rev Respir Dis 1991;143(2):301-5.

21. Zuskin E, Mustajbegovic J, Schachter EN, Pavicic D, Budak A. A follow-up study of respiratory function in workers exposed to acid aerosols in a food-processing industry. Int Arch Occup Environ Health 1997;70:413-8.

22. Zejda JE, Pahwa P, Dosman JA. Decline in spirometric variables in grain workers from start of employment: differential effect of duration of follow up. Br J Ind Med 1992;49(8):576580.

23. Musk AW, Peters JM, Bernstein L, Rubin C, Monroe CB. Pulmonary function in firefighters: a six-year follow-up in the Boston Fire Department. Am J Ind Med 1982;3(1):3-9.

24. Christiani DC, Wang XR, Pan LD, Zhang HX, Sun BX, Dai $\mathrm{H}$, et al. Longitudinal changes in pulmonary function and respiratory symptoms in cotton textile workers: a 15 -yr follow-up study. Am J Respir Crit Care Med 2001;163(4):84753.

25. Pham QT, Mur JM, Teculescu D, Chau N, Gabiano M, Gaertner $\mathrm{M}$, et al. A longitudinal study of symptoms and respiratory function tests in iron miners. Eur J Respir Dis 1986;69(5):346-54.

26. Mur JM, Pham QT, Teculescu D, Massin N, Meyer-Bisch C, Moulin JJ, et al. Arc welders respiratory health evolution over five years. Int Arch Occup Environ Health 1989;61:3217.

27. Pham QT, Benis AM, Mur JM, Sadoul P, Haluszka J. Followup study of construction workers with obstructive lung diseases. Scand J Respir Dis 1977;58(4):215-26.

Received for publication: 7 December 2001

\section{Appendix}

\section{Studies considered for this meta-analysis}

Number of papers

Review articles 6

Case reports

Cross-sectional surveys

Case-referent studies 7

Retrospective cohort studies

Experimental studies

Mortality studies

Nonoccupational cohorts or population-based studies

Different paper on the same cohort included

Data on baseline prevalence of chronic bronchitis not reported for those lost to follow-up

Total 